\title{
UTILIZAÇ̃̃O DE DEA PARA ANÁLISE DE PROCESSOS LICITATÓRIOS ESTUDO DE CASO DO PROCESSO DE CONTRATAÇÃO DE EMBARCAÇÕES DE APOIO MARÍTIMO OFFSHORE DA PETROBRAS
}

\author{
Gustavo da Silva Maciel ${ }^{1}$ \\ Lidia Angulo Meza² \\ Vanderson Lopes Felix da Silveira ${ }^{3}$
}

\begin{abstract}
Resumo: O presente trabalho apresenta um caso de utilização da Análise Envoltória de Dados (DEA) em processos licitatórios. Discute-se a utilidade de DEA para a redução do grau de subjetividade presente no processo de contratação de embarcações de apoio marítimo offshore, sobretudo quando se trata da modalidade de licitação "melhor técnica e preço". Como resultado, verifica-se que a aplicação de DEA pode ser um grande aliado na tomada de decisão porque permite uma melhor ordenação das propostas concorrentes e, no fim, a contratação da melhor frota com atendimento dos requisitos técnicos, econômicos e legais.
\end{abstract}

Palavras-chave: Análise Envoltória de Dados; Processos licitatórios; Embarcações de apoio marítimo.

Abstract: This paper presents a case of using the Data Envelopment Analysis (DEA) application in bidding processes. It discusses the usefulness of DEA for reducing the degree of subjectivity present in the hiring process for offshore marine support vessels, especially when it comes to the method of auctioning "best technical and price." As a result, it appears that this application can be a great ally in decision making process as it allows a better ordering of the proposals and, in the end, the hiring of the fleet with better care of technical, economical and legal criteria.

Keywords: Data Envelopment Analysis; Bidding Process; Offshore Vessels.

\section{INTRODUÇÃO}

Na Administração Pública brasileira, a contratação de obras, serviços e compras, salvo alguns casos prescritos em lei, deve ser realizada por meio de procedimento licitatório. Nesse contexto, a PETROBRAS (Petróleo Brasileiro S.A.), que tem como acionista principal o governo brasileiro, deve seguir tal procedimento.

A PETROBRAS possui, na área de Exploração e Produção de Petróleo e Gás Natural, uma frota terceirizada de embarcações de apoio marítimo offshore para o suprimento de unidades marítimas de produção. E é justamente o processo de contratação de tais embarcações que será o objeto de análise deste artigo. Com a aplicação de DEA na avaliação, espera-se estar contribuindo para a contratação de uma frota de embarcações que melhor atenda, também, aos requisitos técnicos e não apenas ao econômico (preço ou custo), que é o que normalmente ocorre mesmo quando a modalidade de licitação é a de "melhor técnica e preço".

O trabalho proposto visa aplicar um Modelo de Análise Envoltória de Dados (DEA) para auxiliar à tomada de decisão na contratação embarcaçõos de apoio. Para isso, um breve resumo dos principais conceitos da técnica DEA serão apresentados: o modelo CCR, o modelo BCC, as duas orientaçóes (orientação a inputs e orientação a outputs) e o método da fronteira invertida.

\footnotetext{
Petróleo Brasileiro S/A - PETROBRAS, gustavomaciel@petrobras.com.br

Universidade Federal Fluminense - UFF, lidia_a_meza@yahoo.com

Petróleo Brasileiro S/A - PETROBRAS, vansilveira@petrobras.com.br
} 
Posteriormente, serão apresentados e discutidos os resultados da aplicação de DEA no caso proposto. Em seguida, virão a conclusão e as sugestões para trabalhos futuros.

Como no presente artigo, as embarcações marítimas que concorrem no procedimento licitatório são similares em tecnologia e estão sujeitas a condições operacionais semelhantes, será adotado o Modelo DEA-CCR em conjunto com o Método da Fronteira Invertida, que é usado para resolver o problema da pouca diferenciação das DMUs.

$\mathrm{Na}$ modelagem do estudo de caso, as DMUs (Decision Making Units) serão as propostas concorrentes na licitação (embarcaçôes de apoio) entre as quais se deseja selecionar a vencedora - e as variáveis serão os requisitos econômicos (preço, inclusive) e técnicos através dos quais as DMUs serão comparadas.

\section{A ANÁLISE ENVOLTÓRIA DE DADOS}

Originalmente elaborada por Charnes, Cooper e Rhodes (1978), Data Envelopment Analysis (DEA) ou Análise Envoltória de Dados é uma técnica que, a partir de dados observados, utiliza recursos de programação linear para mensurar o desempenho e que tem como objetivo principal determinar a eficiência relativa de unidades de produção similares (Decision Making Units - DMUs) que transformam insumos em produtos (Bougnol et al., 2009). Ainda segundo Bougnol et al. (2009), a Análise Envoltória de Dados pode ser interpretada como uma generalização natural de práticas elementares de avaliação de eficiência e desempenho já utilizadas em diversas áreas. Em outras palavras, DEA não faz nada além de utilizar conceitos de avaliação já consolidados no mundo real de negócios para tomada de decisão.

Desde já, ressalta-se a condição relativa do conceito de eficiência. Ela compara o que foi produzido, dados os recursos disponíveis, com o que poderia ter sido produzido com os mesmos recursos (Soares de Mello et al., 2005).

Ao contrário dos chamados métodos paramétricos, a Análise Envoltória de Dados não supõe nenhuma relação funcional pré-definida entre os recursos e o que foi produzido (Soares de Mello et al., 2005). Além disso, formalmente, DEA prima por ser uma metodologia de fronteira e, não, de tendência central (Cooper et al.,
2000). Portanto, é diferente de métodos paramétricos como a Análise de Regressão porque não desconsidera pontos "outliers", ou seja, que se localizam fora de uma linha de tendência. Ao contrário, esses pontos "fora da curva" também compõem a medida de eficiência de cada DMU já que DEA considera que o máximo que poderia ter sido produzido por uma DMU foi obtido por meio da observação das unidades mais produtivas (Soares de Mello et al., 2005).

A Análise Envotória de Dados, por conseguir compor uma única medida (eficiência) a partir de várias variáveis (insumos e produtos) não necessariamente correlacionadas e por fazer uma comparação da eficiência das diferentes unidades de produção (DMUs), tem encontrado crescente aplicação. Importante salientar que em DEA o termo produção possui sentido amplo e não está necessariamente relacionado a nenhum tipo de produção física (Soares de Mello et al., 2008). Além disso, uma vantagem de DEA é o fato de ela permitir que as variáveis (recursos e produtos) com que as DMUs serão comparadas sejam quaisquer, desde que sejam quantitativas e sejam as mesmas para todas elas (unidades monetárias, recursos humanos, etc.).

A Análise Envoltória de Dados vai além do cálculo das eficiências das DMUs e da classificação das DMUs em eficientes e não eficientes. Ela também indica a forma como as DMUs ineficientes podem se tornar eficientes. Basicamente, a metodologia DEA fornece quatro tipos de resultados:

1. Índice de eficiência: separa as unidades eficientes das ineficientes. Uma DMU é considerada eficiente quando o seu índice de eficiência é igual à unidade. Pelo conceito de eficiência de Pareto, todas essas unidades comporão a fronteira eficiente. Uma unidade é Pareto eficiente se, e somente se, ela não consegue melhorar alguma de suas características sem piorar as demais (Soares de Mello et al., 2005). Em contrapartida, serão ineficientes aquelas cujo índice for inferior a 1. Ele pode ser obtido tanto do do PPL primal de DEA (Modelo dos Multiplicadores) quanto do PPL dual (Modelo do Envelope). No item 2.1, esses dois PPLs serão vistos mais detalhadamente;

2. Pesos de cada variável: como solução do PPL primal (Modelo dos Multiplicadores), cada DMU terá um peso associado a cada variá- 
vel. Para uma mesma DMU, a multiplicação dos pesos pelo valor da respectiva variável dá o índice de eficiência de cada DMU. O conjunto dos pesos é o vetor que maximiza ou minimiza a função objetivo do PPL de cada DMU. Como será visto mais adiante, os pesos das variáveis não estão presentes na formulação da PPL do Modelo do Envelope (nem da função objetivo nem das restrições;

3. Metas para as DMUs ineficientes: indicação do que cada DMU ineficiente deve fazer para se tornar eficiente. Isso é possível porque DEA determina a que distância da fronteira de eficiência estão as unidades ineficientes. Dependendo da orientação do modelo, essa meta poderá ser ou manutenção/ redução dos recursos (orientação a inputs) ou manutenção/incremento dos produtos (orientação a outputs). A indicação das metas vem do Modelo do Envelope;

4. Identificação das DMUs benchmarks ou alvos (conjunto de referência): para cada DMU ineficiente, indica-se, como referência, uma ou mais DMUs eficientes (conjunto de referência). É a indicação de como as DMUs ineficientes podem atingir suas metas no sentido de se tornarem eficientes. Também é resultado do Modelo do Envelope.

$\mathrm{Na}$ literatura, encontram-se inúmeras formulações de modelos de DEA (Coelli et al., 1998) e, a partir de todas elas, é possível obter os quatro resultados supracitados. Todavia, dois deles são considerados clássicos: o CCR e o BCC. É importante não confundir a classificação em Modelo CCR ou BCC com a que se faz em Modelo dos Multiplicadores e Modelo do Envelope. $\mathrm{Na}$ verdade, cada modelo CCR ou BCC - seja na orientação a input ou na orientação a output - é a formulação matemática de um problema de programação linear (PPL). Sendo assim, eles possuem um PPL primal e um dual.

\subsection{MODELO CCR}

Em 1978, Charnes, Cooper e Rhodes formalizaram o modelo inaugural de DEA: o modelo CCR. O modelo DEA-CCR é um modelo multidimensional (múltiplos recursos e múltiplos produtos) que constrói uma superfície linear por partes, não paramétrica, envolvendo os dados (Soares de Mello et al., 2005). Ele está baseado no conceito de retornos constantes de escala (fronteira CRS - constant returns of scale $)^{4}$, isto é, qualquer variação nos insumos (inputs) produz variação proporcional nos produtos (outputs). Dependendo do objetivo da modelagem e do caso modelado, o modelo CCR poderá tomar as seguintes orientações: orientação a inputs ou orientação a outputs.

O modelo DEA-CCR orientado a inputs determina a eficiência pela otimização da divisão entre a soma ponderada das saídas (output virtual) e a soma ponderada das entradas (input virtual). Ele permite que cada DMU escolha os pesos para cada variável (recursos e produtos) da forma que lhe for mais benevolente, desde que esses pesos aplicados às outras DMUs não gerem uma razão superior a 1 (Soares de Mello et al., 2005). Na verdade, na formulação matemática do PPL de DEA, os pesos $\left(\mathrm{u}_{\mathrm{i}}\right.$ e $\left.\mathrm{v}_{\mathrm{i}}\right)$ são as variáveis de decisão. Assim sendo, obtém-se o resultado, isto é, chega-se ao valor dessas variáveis de decisão de acordo com a função objetivo desse PPL. A formulação matemática do PPL primal - chamado Modelo dos Multiplicadores - do modelo DEA-CCR orientado a inputs, já linearizada, é o modelo apresentado em (1).

\section{$\operatorname{Max} E f f_{o}=\sum_{j=1}^{s} u_{j} y_{j o}$}

sujeito a

$$
\begin{aligned}
& \sum_{i=1}^{r} v_{i} x_{i o}=1 \\
& \sum_{j=1}^{j} u_{j} y_{j k}-\sum_{i=1}^{r} v_{i} x_{i k} \leq 0, \forall k \\
& v_{i}, u_{j} \geq 0, \forall i, j
\end{aligned}
$$

A estrutura matemática desses modelos permite que uma DMU seja considerada eficiente (função objetivo igual a 1) com vários conjuntos de pesos diferentes (Soares de Mello et al., 2005). Como é um PPL com número de variáveis, quase sempre, maior que o número de restriçōes, a possibilidade de múltiplas soluções ótimas é grande. É bastante comum a obtenção de pesos diferentes - mantendo a mesma eficiência - apenas com a mudança na ordem das restrições do PPL. É o problema da multiplicidade das ótimas soluções

4 É importante não confundir as nomenclaturas dos conceitos. O modelo CCR leva esse nome, devido às iniciais

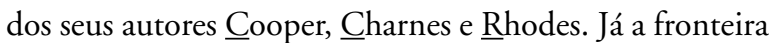
se chama CRS (onstant returns of s scale). 
em DEA. Segundo Soares de Mello et al. (2005), em particular, podem ser atribuídos pesos zeros a algum input ou output, o que significa que essa variável foi desconsiderada na avaliação naquele PPL. Entretanto, não se pode dizer que uma DMU está ignorando determinada variável. Para afirmar isso, é preciso passar por todas as soluções ótimas. Por isso, os pesos obtidos não significam importância. Eles são multiplicadores (daí o nome do modelo) que vão compor o índice de eficiência.

Este modelo é orientado a inputs porque a eficiência é atingida com a redução dos recursos e isso pode ser visto de forma mais clara a partir da formulação dual desse PPL, chamado Modelo do Envelope. Por ser dual, a função objetivo também representa a eficiência, que nada mais é do que o valor pelo qual todos os inputs devem ser multiplicados para que a DMU se posicione na fronteira eficiente. Sua formulação é a do modelo (2).

\section{$\operatorname{Min} h_{o}$}

\section{sujeito a}

$$
\begin{aligned}
& h_{o} x_{j o}-\sum_{k=1}^{n} x_{i k} \lambda_{k} \geq 0, \forall i \\
& -y_{j o}+\sum_{k=1}^{n} y_{j k} \lambda_{k} \geq 0, \forall j \\
& \lambda_{k} \geq 0, \forall k
\end{aligned}
$$

O Modelo do Envelope orientado a input tentará reduzir o consumo dos recursos até o limite da fronteira eficiente, mantendo o output. Isso pode ser claramente visto pelas restrições do seu PPL. Repara-se que há dois grupos de restrições: o primeiro deles garante que a redução em cada um dos inputs não ultrapasse a fronteira definida pelas DMUs eficientes; o segundo garante a manutenção do nível atual dos outputs daquela DMU (Soares de Mello et al., 2005).

No Modelo do Envelope, as variáveis de decisão não são os pesos das variáveis e, sim, $h_{\text {o }}$ e $\lambda$ 's. O termo $h_{o}$ é o fator de redução da DMU analisada e será o mesmo para todos os inputs. Por sua vez, os $\lambda$ 's indicam com que intensidade cada uma das demais DMUs contribuem para tornar eficiente a DMU em análise. Naturalmente, quando o $\lambda$ associado a uma DMU for igual a zero, significa que essa DMU não contribui em nada para tornar eficiente a DMU analisada. Por outro lado, as DMUs com $\lambda$ diferente de zero serão as unidades de produção de referência (benchmarks ou alvos) para a unidade de produção em análise. A figura 1 (Soares de Mello et al., 2005) mostra a interpretação gráfica dos $\lambda$ 's para uma modelagem com 2 inputs e 1 output (orientação a input).

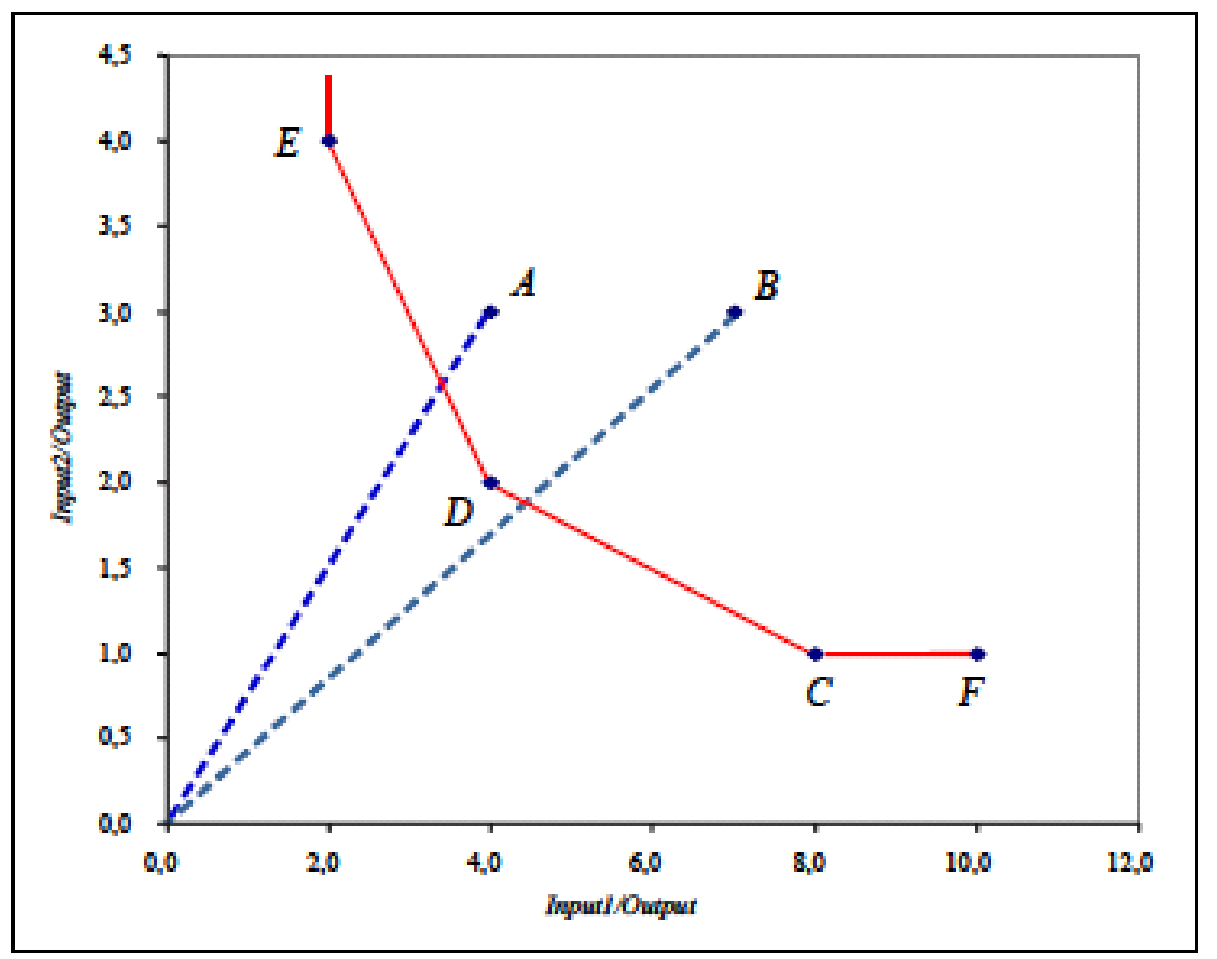

Figura 1 - Modelo CCR orientado a input (2 inputs e 1 output) - projeção radial e alvos 
$\mathrm{Na}$ figura acima, as DMUs C, D, E e F são eficientes e as DMUs A e B são ineficientes. As linhas tracejadas que ligam as DMUs ineficientes à origem (cor azul) indicam a projeção das DMUs ineficientes na fronteira eficiente (projeção radial). A projeção radial da DMU A, por exemplo, intercepta o segmento de reta ED da fronteira, o que indica que as DMUs E e D (eficientes) são os benchmarks da DMU A e que a DMU D contribui mais fortemente para tornar a DMU A eficiente do que a DMU E (o intercepto está mais próximo da DMU D que da DMU E). Interessante observar também que a DMU C, eficiente, não é benchmark para a DMU A. Nesse caso, o $\lambda_{C}$ é igual a 0 .

No Modelo dos Multiplicadores DEACCR orientado a outputs, as variáveis de decisão são as mesmas do modelo orientado a inputs, com a diferença de que se maximizam os produtos, mantendo-se inalterados os recursos. Já no Modelo do Envelope, o $\mathrm{h}_{\mathrm{o}}$ representa por quanto todos os produtos devem ser multiplicados para a DMUo se tornar eficiente (Soares de Mello et al., 2005). Dessa forma, $h_{o}$ é maior que 1 e a eficiência é $1 / h_{0}$. Dada uma DMU, as duas orientações do modelo DEA-CCR fornecem o mesmo valor de eficiência.

\subsection{MODELO BCC}

O modelo DEA-BCC substitui o axioma da proporcionalidade pelo axioma da convexidade, isto é, considera retornos variáveis de escala (fronteira VRS - variable returns of scale) (Banker et al., 1984). Matematicamente, no Modelo dos Multiplicadores orientado a input, a convexidade está representada pela inclusão do fator de escala $\left(\mathrm{u}_{*}\right)$. Já no Modelo do Envelope, essa convexidade equivale a uma restrição adicional. As formulações respectivas estão em (3) e em (4) (Soares de Mello et al., 2005). Uma DMU eficiente no modelo CCR também o será no modelo BCC. A recíproca não é verdadeira, porque o modelo DEA-BCC, por considerar retornos variáveis de escala, tende a ser mais benevolente do que o DEA-CCR no cálculo das eficiências das DMUs.
$\operatorname{Max} E f f_{o}=\sum_{j=1}^{s} u_{j} y_{j o}+u_{*}$

sujeito a

$\sum_{i=1}^{r} v_{i} x_{i 0}=1$

$-\sum_{i=1}^{r} v_{i} x_{i k}+\sum_{j=1}^{s} u_{j} y_{j k}+u_{*} \leq 0, \forall k$

$v_{i}, u_{j} \geq 0, u, \in \Re$

$$
\begin{aligned}
& \text { Min } h_{o} \\
& \text { sujeito a } \\
& h_{o} x_{s o}-\sum_{k=1}^{n} x_{i k} \lambda_{k} \geq 0, \forall i \\
& -y_{j o}+\sum_{k=1}^{n} y_{j k} \lambda_{k} \geq 0, \forall j \\
& \sum_{k=1}^{n} \lambda_{k}=1 \\
& \lambda_{k} \geq 0, \forall k
\end{aligned}
$$

Para este estudo de caso, foi escolhido o modelo CCR. Ao contrário do Modelo BCC, ele é o mais indicado quando as DMUs possuem tecnologias semelhantes ou operam nas mesmas condições. Afinal, as embarcaçōes avaliadas irão operar nas mesmas condições geográficas (de clima, ventos e marés, etc.) e as diferenças técnicas apresentadas não significam patamares tecnológicos distintos entre as propostas concorrentes.

Adotou-se o modelo DEA-CCR porque os próprios dados coletados das DMUs indicam uma relação mais uniforme entre as escalas das mesmas. Quando isso ocorre, a modelagem pelo DEA-BCC não se mostra adequada (Banker et al., 1984).

\subsection{MÉTODO DA FRONTEIRA INVERTIDA}

Apesar das vantagens dos modelos DEA, sobretudo em relação aos modelos paramétricos, os modelos DEA (CCR e BCC) geralmente resultam em um grande número de DMUs eficientes. Isso porque, pela formulação matemática, eles tendem a ser benevolentes com as unidades de produção avaliadas (o BCC ainda mais que o CCR) (Soares de Mello et al., 2005). As principais razões para pouca discriminação entre as DMUs são as seguintes (Ângulo Meza et al., 2002): 
- O número de DMUs é pequeno em relação ao número total de variáveis em análise;

- Multiplicidade de soluções ótimas na atribuição de pesos de DMUs fortemente eficientes.

Para o problema de pouca discriminação das DMUs em DEA, há dois grupos de métodos: um grupo cujos métodos demandam a incorporação de informações a priori sobre as variáveis (opinião dos tomadores de decisão, por exemplo); e outros que não exigem nenhuma informação prévia (Ângulo Meza et al., 2002). O Método da Fronteira Invertida compóe esse segundo grupo.

O Método da Fronteira Invertida é um método que mantém o perfil de objetividade do método DEA. Seu conceito foi introduzido por Yamada et al. (1994) e Entani et al. (2002). Na sua modelagem, faz-se uma inversão entre os inputs e os outputs do modelo original. Esta fronteira invertida é composta pelas DMUs com as piores práticas gerenciais (e podemos chamá-la de fronteira ineficiente). Pode-se afirmar que as DMUs pertencentes à fronteira invertida têm as melhores práticas sob uma ótica oposta (Soares de Mello et al., 2005). Desde já, portanto, temse como esclarecido que o Método da Fronteira Invertida é uma proposta diferente do método DEA-CCR clássico.

Neste artigo, o resultado final (índice de eficiência e ordenação das DMUs) será de acordo com o índice de eficiência composta, cuja fórmula está em (5). É uma terceira abordagem, cujo resultado é diferente do obtido com a utilização exclusiva de DEA-CCR clássico (eficiência padrão) e diferente daquele obtido na Fronteira Invertida do DEA-CCR (eficiência invertida). Portanto, para melhorar a classificação obtida pelo método clássico (será vista no item 4) será adotado um índice de eficiência que é a média aritmética da eficiência segundo as óticas otimista e pessimista, observada em (5) (Soares de Mello et al., 2005).

Eficiência $_{\text {composta }}=\frac{\text { Eficiência }_{\text {padrão }}-\text { Eficiência }_{\text {invertida }}+1}{2}$

\section{ESTUDO DE CASO}

Baseada na lei federal no 8.666, de 21 de junho de 1993, a Administração Pública brasilei- ra encontra regulamentação e detalhamento para elaboração de seus processos licitatórios.

Tal como um procedimento, a supracitada lei federal tem o objetivo de garantir os preceitos do caput do artigo 37 da Constituição Federal de 1988: "A administração pública direta e indireta de qualquer dos Poderes da União, dos Estados, do Distrito Federal e dos Municípios obedecerá aos princípios de legalidade, impessoalidade, moralidade, publicidade e eficiência...”. Além desses princípios, a licitação deve observar também os da vinculação ao instrumento convocatório, da economicidade e do julgamento objetivo, destinando-se a selecionar a proposta mais vantajosa para o fim pretendido.

A PETROBRAS, como instituição pertencente à Administração Pública brasileira, segue as normas estabelecidas e utiliza a licitação em diversas atividades. Uma delas é o foco do presente trabalho: planejamento logístico para transporte de cargas e suprimentos, indispensável para a continuidade operacional de plataformas de exploração e produção de petróleo e gás natural. Nessa atividade, são utilizadas embarcações de apoio marítimo ao longo de toda a costa brasileira onde se localizam bacias de exploração e produção da PETROBRAS.

As embarcaçōes de apoio marítimo são recursos críticos que têm tido uma demanda crescente no mercado brasileiro de produção de petróleo e gás offshore e, com o desenvolvimento dos campos da camada do Pré-sal, a expectativa é de que, nos próximos anos, esse nicho esteja ainda mais alavancado.

Pelo lado da oferta, há dois importantes fatores de criticidade dessas embarcações: o preço e as condiçōes operacionais. Apesar de possuírem um porte menor, o preço de aquisição de uma embarcação de apoio do tipo AHTS (ANCHOR HANDLING TUG SUPPLY) ou PSV (PLATFORM SUPPLY VESSEL) pode ser igual ou superior ao de uma embarcação mercante convencional. Isso se deve aos altos custos dos equipamentos instalados numa embarcação de apoio desse tipo. Outra diferença notável está nas condições de operação: enquanto na maioria das embarcações mercantes importam apenas as condiçōes de operação nos momentos de partida, de chegada e definição de rota porto a porto, as embarcaçôes de apoio marítimo operam também paradas, ou seja, elas devem manter seu posicionamento no mar para realizar as operaçôes de suprimento com as unidades offshore. Com isso, estão sujeitas às condições 
ambientais da região de operação (ação de ondas, ventos e correntes marinhas), o que só aumenta a severidade dos serviços a serem realizados.

Todas essas características impõem uma dificuldade no estabelecimento da melhor relação custo-benefício na contratação dessas embarcações de apoio. Por essas razôes, em conformidade com o texto do artigo $46, \$ 3^{\circ}$ da lei 8.666/93, a PETROBRAS realiza, na contratação de embarcaçōes de apoio, as licitações pelo tipo "melhor técnica e preço". Ela é mais adequada quando estão em jogo atributos de preço e qualidade técnica. Como há uma linha muito tênue separando os critérios objetivos dos subjetivos, a adoção da "melhor técnica e preço" exige rigor na definição dos critérios de avaliação das propostas. Mais do que isso, o edital de licitação, sob o princípio do julgamento objetivo, não poderá conter critérios subjetivos. Pelo contrário, ele deverá propor, de forma clara, somente critérios objetivos que lhe dêem máxima transparência.

Normalmente, o processo licitatório é conduzido em duas etapas. $\mathrm{Na}$ primeira etapa, são aprovadas aquelas propostas técnicas que atenderem minimamente aos requisitos técnicos (pontuação mínima). Então, as propostas técnicas classificadas, seguem para a abertura da proposta de preços. Dessa forma, o processo dá por vencedora aquela embarcação com menor preço dentre aquelas que obtiveram a pontuação mínima. Portanto, numa análise inicial, os princípios de eficiência e economicidade foram atendidos e o objetivo da licitação foi alcançado. Ocorre que, durante o período de vigência do contrato (após o processo licitatório), não raras são as vezes em que se observa uma série de problemas técnico-operacionais que resultam em dispêndios adicionais. Como conseqüência, a contratação, antes a mais barata, torna-se muito cara e o objetivo de economicidade, de fato, acaba não sendo atendido.

Outros autores como Narasimhan et al. (2001) e Lorentziadis (2010), estudaram métodos para otimização dos processos licitatórios. Entretanto pode ser considerado inovador a aplicação de DEA para determinação do ranking em processos licitatórios.

\section{MODELAGEM E RESULTADOS}

Ao analisar o problema de contratação de embarcações offshore, foi observado que seriam necessárias sete variáveis para descrever a modelagem do processo licitatório, com enfoque em embarcações do tipo PSV (PLATFORM SUPPLY VESSEL), similares à embarcação da figura 2.

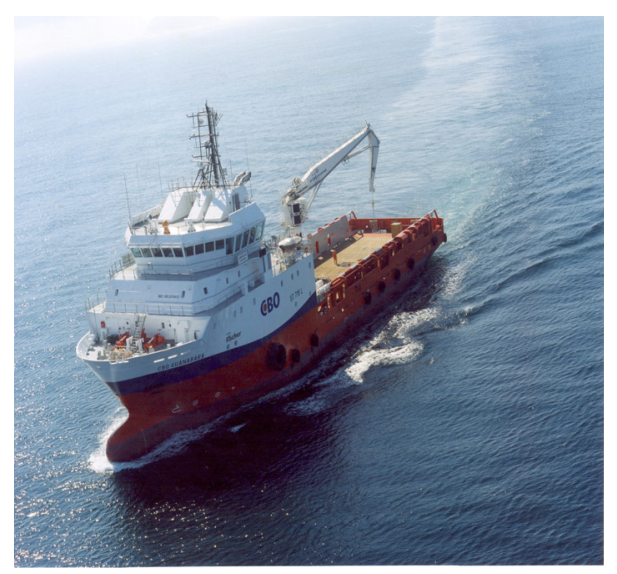

Figura 2 - Embarcação tipo PSV

Tais embarcações transportam em seu convés cargas e equipamentos necessários para o suprimento de unidades marítimas, assim como observado na figura 3 .

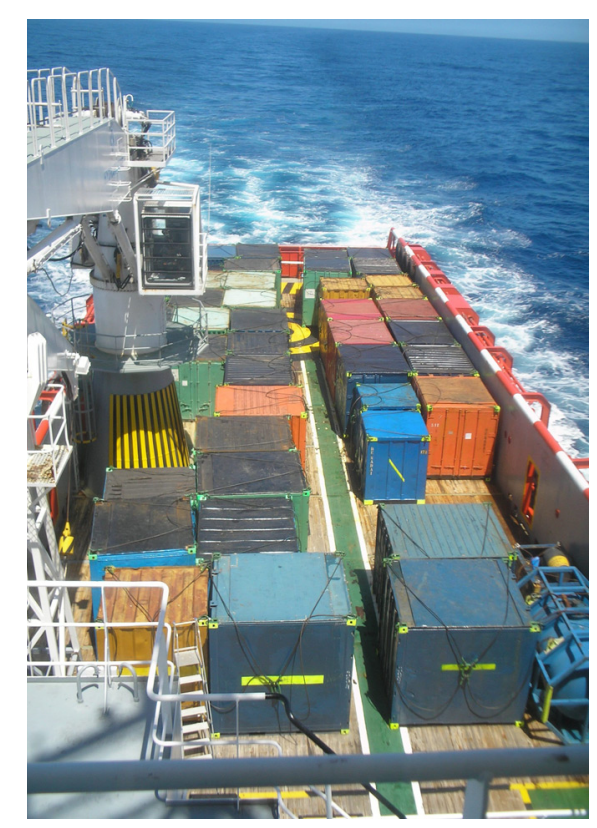

Figura 3 - Embarcação carregada

Além da carga de convés, as embarcaçōes tipo PSV devem possuir tanques capazes de transportar água e óleo diesel, para abastecimento das plataformas. Na figura 4, é possível observar a embarcação próxima a uma unidade offshore, pronta para fazer a transferência de líquido (água) através de mangotes apropriados. 


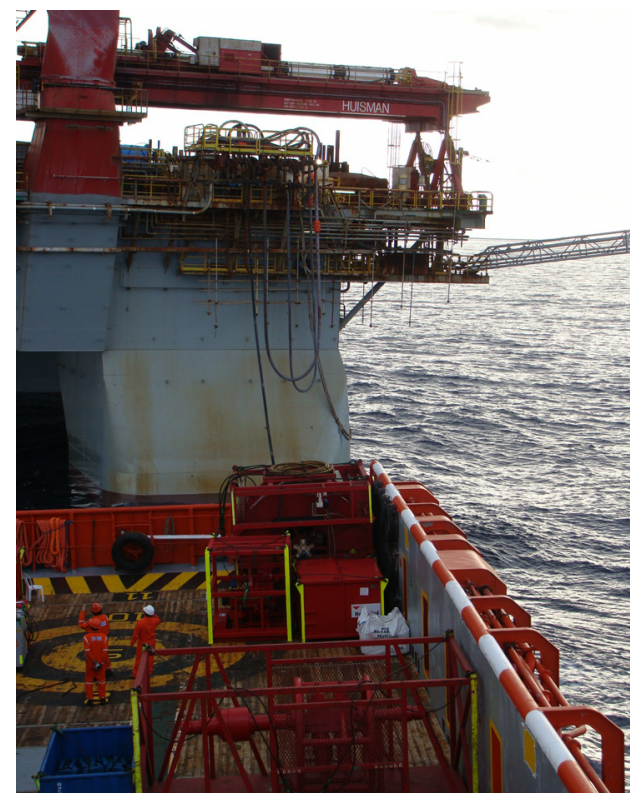

Figura 4 - Transferência de Água

Com isso, para atendimento as plataformas, são necessárias que as embarcações tipo PSV possuam área livre de convés e tanques para o transporte de líquidos, segregados para o transporte de água e diesel, para garantir a flexibilidade operacional no suprimento das unidades marítimas. Tais características devem estar associadas a uma potência e velocidade de navegação adequada ao atendimento as unidades produtoras localizadas a quilômetros da costa.

Como a PETROBRAS contrata essas embarcações através de processos licitatórios, deve-se minimizar o impacto financeiro através da contratação de embarcações mais econômicas, ou seja, que consuma pouco combustível, além de pagar taxas diárias de afretamento menores, além de buscar a otimização do suprimento as unidades offshore.

Sendo assim, o problema será modelado com duas variáveis de entrada (Inputs) e cinco variáveis de saída (outputs), descritas da seguinte maneira:
- Input 1: Valor da Taxa Diária ofertada para cada embarcação (DMU) (em dólares norte-americanos);

- Input 2: Consumo de Combustível da embarcação (em toneladas por dia);

- Output 1: Capacidade Total de armazenamento de água potável (em metroscúbicos);

- Output 2: Capacidade Total de armazenamento de óleo diesel (em metroscúbicos);

- Output 3: Capacidade Total de armazenamento de carga de convés (em metrosquadrados);

- Output 4: Potência Máxima Contínua de Propulsão da embarcação (em BHP - unidade de potência);

- Output 5: Velocidade Máxima a ser atingida durante a navegação da embarcação (em nós - milhas náuticas por hora).

No estudo em questão será adotado o Modelo DEA-CCR com orientação a inputs, já que se tem como objetivo minimizar a taxa diária de afretamento da embarcação e o consumo de combustível, o qual é pago pela PETROBRAS. Nota-se que os outputs não são controláveis e, portanto, são variáveis não discricionárias. Entretanto, tal fato não é relevante nessa modelagem, já que o objetivo é reduzir os inputs, mantendo os outputs constantes, que é a definição da orientação a inputs.

Após a definição das variáveis, foram coletados os seguintes dados, observados na tabela 1 , os quais foram obtidos de processos licitatórios recentes. Entretanto, os mesmos estão normalizados devido à confidencialidade das informaçôes. A presente modelagem é composta de 20 DMUs, ou seja, no processo licitatório estudado concorreram 20 embarcações diferentes.

Tabela 1 - Dados de Embarcações PSVs

\begin{tabular}{|c|c|c|c|c|c|c|c|}
\hline & Taxa & Consumo & Água & Diesel & Carga & Potência & Velocidade \\
\hline PSV_1 & 18000 & 22.9 & 1500 & 800 & 500 & 5460 & 13 \\
\hline PSV_2 & 19000 & 22 & 1550 & 830 & 520 & 5600 & 13.5 \\
\hline PSV_3 & 20000 & 22.5 & 1580 & 870 & 560 & 5400 & 13.8 \\
\hline PSV_4 & 21000 & 22.1 & 1650 & 890 & 600 & 5300 & 12.7 \\
\hline PSV_5 & 22000 & 21.9 & 1630 & 850 & 500 & 5290 & 11.3 \\
\hline PSV_6 & 23000 & 21.7 & 1610 & 820 & 490 & 5700 & 12.7 \\
\hline
\end{tabular}




\begin{tabular}{|c|c|c|c|c|c|c|c|}
\hline PSV_7 & 23500 & 22.6 & 1590 & 900 & 450 & 5800 & 15.1 \\
\hline PSV_8 & 24000 & 22.4 & 1450 & 1000 & 500 & 6000 & 13.4 \\
\hline PSV_9 & 24500 & 23.2 & 1700 & 1100 & 550 & 5800 & 15.6 \\
\hline PSV_10 & 25000 & 24.2 & 1620 & 1020 & 600 & 5900 & 14.7 \\
\hline PSV_11 & 25000 & 21.7 & 1590 & 890 & 530 & 5200 & 13.9 \\
\hline PSV_12 & 25500 & 21 & 1780 & 950 & 490 & 5470 & 13.8 \\
\hline PSV_13 & 26000 & 21.5 & 1730 & 1050 & 520 & 5570 & 11.4 \\
\hline PSV_14 & 26500 & 21.3 & 1640 & 980 & 550 & 5990 & 11.5 \\
\hline PSV_15 & 27000 & 21.2 & 1590 & 990 & 600 & 6000 & 12.3 \\
\hline PSV_16 & 27500 & 20.4 & 1650 & 1040 & 620 & 5580 & 12.3 \\
\hline PSV_17 & 28000 & 20.3 & 1540 & 1060 & 600 & 5730 & 11.5 \\
\hline PSV_18 & 28500 & 21.5 & 1500 & 1100 & 580 & 5500 & 12 \\
\hline PSV_19 & 29000 & 21.7 & 1390 & 1030 & 560 & 5900 & 12.5 \\
\hline PSV_20 & 30000 & 21.4 & 1420 & 970 & 650 & 5300 & 13 \\
\hline
\end{tabular}

De acordo com a Tabela 1, foram analisadas 20 embarcações supridoras para apoio marítimo, representadas pelas DMUs, as quais foram ordenadas de 1 a 20. Tal ordenação foi baseada na forma atual de contratação, descrita como menor preço, ou seja, se as embarcações têm os requisitos técnicos mínimos para atendimento da demanda, as que tiverem os menores preços vencem a licitação.

A ordem de classificação das propostas, baseada apenas na taxa diária de afretamento para a embarcação, pode ser observada na tabela 2 . Conseqüentemente, a embarcação vencedora foi o PSV_1, por ter oferecido a menor Taxa Diária.

Tabela 2 - Classificação das Propostas segundo taxa diária de afretamento

\begin{tabular}{|c|c|}
\hline Ordenação (Menor Preço) & Taxa Diária (USD) \\
\hline PSV_1 & 18000 \\
\hline PSV_2 & 19000 \\
\hline PSV_3 & 20000 \\
\hline PSV_4 & 21000 \\
\hline PSV_5 & 22000 \\
\hline PSV_6 & 23000 \\
\hline PSV_7 & 23500 \\
\hline PSV_8 & 24000 \\
\hline PSV_9 & 24500 \\
\hline PSV_10 & 25000 \\
\hline
\end{tabular}

\begin{tabular}{|l|l|}
\hline PSV_11 & 25000 \\
\hline PSV_12 & 25500 \\
\hline PSV_13 & 26000 \\
\hline PSV_14 & 26500 \\
\hline PSV_15 & 27000 \\
\hline PSV_16 & 27500 \\
\hline PSV_17 & 28000 \\
\hline PSV_18 & 28500 \\
\hline PSV_19 & 29000 \\
\hline PSV_20 & 30000 \\
\hline
\end{tabular}

Com o auxílio do software SIAD (Sistema Integrado de Apoio à Decisão) (Ângulo Meza et al., 2005), foram rodados os dados descritos na tabela 1, para, assim, poder avaliar a eficiência associada a cada DMU (embarcação), considerando tanto critérios técnicos quanto econômicos, conforme descrição das variáveis que foram utilizadas na modelagem. A tabela 3 abaixo demonstra a eficiência encontrada para cada DMU, além de estabelecer alvos para as DMUs ineficientes (eficiência $<1$ ), de acordo com o Método CCR orientado a input.

Analisando a tabela 3, observa-se que, ao abordar o conceito de alvos para as DMUs ineficientes, é possível ser estabelecida a meta, ou seja, por quanto é que a empresa a ser contratada deveria oferecer de proposta para determina- 
da embarcação. Entretanto, esse processo ficaria incompleto, já que foram observadas várias DMUs eficientes, o que dificulta o estabelecimento de um ranking de propostas. Até aqui, com a aplicação do modelo CCR "benevolente", não foi possível fazer uma boa discriminação das DMUs.

Nesse contexto, foi necessário aplicar o Método da Fronteira Invertida, a qual possibilitou o estabelecimento da seguinte classificação das propostas descrita na tabela 4. Tal método foi escolhido devido a sua característica de não necessitar da interferência do decisor, garantindo assim a imparcialidade do processo licitatório.

\section{Tabela 3 - Resultado do Modelo CCR orientado a input}

\begin{tabular}{|c|c|c|}
\hline $\begin{array}{c}\text { Ordenação } \\
\text { (Modelo CCR } \\
\text { e Orientação a } \\
\text { Input) }\end{array}$ & Eficiência & $\begin{array}{c}\text { Alvo } \\
\text { (INPUT 1-Taxa } \\
\text { Diária em USD }\end{array}$ \\
\hline PSV_1 & 1 & - \\
\hline PSV_2 & 1 & - \\
\hline PSV_3 & 1 & - \\
\hline PSV_4 & 1 & - \\
\hline PSV_7 & 1 & - \\
\hline PSV_8 & 1 & - \\
\hline PSV_9 & 1 & - \\
\hline PSV_12 & 1 & - \\
\hline PSV_13 & 1 & - \\
\hline PSV_14 & 1 & - \\
\hline PSV_15 & 1 & - \\
\hline PSV_16 & 1 & - \\
\hline PSV_17 & 1 & - \\
\hline PSV_20 & 1 & 27681,68 \\
\hline PSV_18 & 0.995027 & 22745,90 \\
\hline PSV_6 & 0.988952 & 27681,68 \\
\hline PSV_19 & 0.975532 & \\
\hline PSV_11 & 0.974097 & 23704,75 \\
\hline PSV_5 & 0.972207 & 21388,55 \\
\hline PSV_10 & 0.967930 & 24198,25 \\
\hline & & \\
\hline & 1 & \\
\hline
\end{tabular}

Tabela 4 - Classificação DEA com aplicação da Fronteira Invertidas

\begin{tabular}{|c|c|}
\hline $\begin{array}{c}\text { Ordenação (Melhor } \\
\text { Técnica e Preço) }\end{array}$ & $\begin{array}{l}\text { Eficiência } \\
\text { Composta }\end{array}$ \\
\hline PSV_16 & 1 \\
\hline PSV_2 & 0.998732 \\
\hline PSV_15 & 0.986049 \\
\hline PSV_9 & 0.981876 \\
\hline PSV_3 & 0.958989 \\
\hline PSV_4 & 0.95484 \\
\hline PSV_1 & 0.954084 \\
\hline PSV_7 & 0.954084 \\
\hline PSV_8 & 0.954084 \\
\hline PSV_12 & 0.954084 \\
\hline PSV_13 & 0.954084 \\
\hline PSV_14 & 0.954084 \\
\hline PSV_17 & 0.954084 \\
\hline PSV_20 & 0.954084 \\
\hline PSV_18 & 0.94934 \\
\hline PSV_6 & 0.943544 \\
\hline PSV_19 & 0.93074 \\
\hline PSV_11 & 0.929371 \\
\hline PSV_5 & 0.927568 \\
\hline PSV_10 & 0.927214 \\
\hline
\end{tabular}

Sendo assim, comparando as tabelas 2, 3 e 4, é possível observar que o melhor resultado gerado foi o apresentado pela tabela 4, o qual foi obtido com a aplicação do Modelo DEA-CCR com orientação a input e Análise da Eficiência Composta, baseada na Fronteira Padrão e Fronteira Invertida.

Ao analisar a classificação tradicional dos processos licitatórios, descrita na tabela 2 , é possível observar que no método tradicional vence a proposta de menor preço, independente das características técnicas das embarcações. Portanto, não existe uma Análise Custo-Benefício das embarcações propostas na licitação. Tal modelo tradicionalista pode favorecer a contratação de recursos que possivelmente terão problemas operacionais no futuro, com isso deveria ser aplicado em contratações de curto prazo, o que não é observado na prática.

A aplicação apenas do Modelo CCR com orientação a input resultou várias embarcaçōes efi- 
cientes, conforme observado na tabela 3 , o que dificulta o estabelecimento de um ranking de propostas.

Em contrapartida, a aplicação do Modelo DEA, com análise da Fronteira Invertida, descrita na tabela 4 , demonstra que a alternativa de "melhor preço" vence, ou seja, a melhor proposta tendo como base a análise conjunta das variáveis técnicas e econômica. Sendo assim, é possível observar que tal método favorece a contratação da melhor embarcação para atendimento das atividades operacionais.

A comparação entre os resultados obtidos pelos dois métodos discutidos na presente seção pode ser observada na tabela 1 . Ao observar as variáveis do PSV_1 (vencedor do Modelo Tradicional) e do PSV_16 (vencedor do Modelo DEA com Análise da Fronteira Invertida), é possível concluir que o PSV_16 é mais econômico, no que diz respeito ao consumo de combustível e tem uma capacidade operacional de transporte muito superior à da embarcação PSV_1.

Procedimentos licitatórios que consideram apenas variáveis econômicas ou aqueles que, na prática, acabam por valorizar mais os critérios econômicos não podem ser considerados eficientes, tendo em vista apenas a visão pontual voltada para o fator econômico. Portanto, a aplicação de métodos para auxílio na tomada de decisão que englobem fatores de julgamento tanto para as variáveis técnicas quanto para as econômicas é a solução mais apropriada para análise de processos licitatórios do tipo "melhor técnica e preço".

\section{COMENTÁRIOS FINAIS}

O Modelo CCR com orientação a inputs, combinado com a Análise da Fronteira Invertida, pode ser considerado uma boa metodologia para a uma melhor condução dos processos licitatórios (aspectos técnicos, econômicos e legais), assim como demonstrado para o caso da contratação de embarcações de apoio marítimo da PETROBRAS.

A aplicação da metodologia proposta nos processos de contratação de embarcações da PETROBRAS resultará na otimização da sua frota de supridores, através do julgamento combinado dos critérios técnicos e econômicos na busca do melhor custo para a Companhia e mais adequação aos aspectos legais.
Para trabalhos futuros, propõe-se a utilização de modelos mais eficientes de DEA que melhorem ainda mais a ordenação gerada para análise dos processos de contratação de embarcaçôes offshore.

Uma nova modelagem poderia incluir uma variável sobre desempenho da empresa em contratos anteriores, levando-se em conta o histórico operacional da empresa.

Outro enfoque poderia incluir a importância das variáveis ou incluir variáveis categóricas, tais como as que descrevem o posicionamento dinâmico da embarcação.

\section{REFERÊNCIAS BIBLIOGRÁFICAS}

Angulo Meza, L., Estellita Lins, M. P. Review of Methods for Increasing Discrimination in Data Envelopment Analysis. Annals of Operations Research, v. 116, p. 225-242, 2002.

Angulo Meza, L.; Biondi Neto, L.; Soares de Mello, J.C.C.B.; Gomes, E.G. ISYDS - Integrated System for Decision Support (SIAD - Sistema Integrado de Apoio à Decisão): a software package for data envelopment analysis model. Pesquisa Operacional, v. 25, n. 3, pp. 493-503, 2005.

Banker, R. D., Charnes, A., Cooper, W. W., Some models for estimating technical and scale inefficiencies in Data Envelopment Analysis. Management Science, v. 30, 9, p. 1078-1092, 1984.

Bougnol, M. L., Dulá, J. H., Estellita Lins, M. P., Moreira da Silva, A. C. Enhancing standard performance practices with DEA. Omega, v. 38, p. 33-45, 2009.

BRASIL. Constituição (1988). Constituição da República Federativa do Brasil. Brasília, DF, Senado, 1998.

BRASIL. Lei no 8.666 de 21 de junho de 1993. Institui normas para licitaçóes e contratos da Administração Pública e dá outras providências. Disponível em: http://www6.senado.gov.br/legislacao/ListaPublicacoes.action?id=102446. Acesso em 17 dez. 2009.

Charnes, A., Cooper, W. W., Rhodes, E. Measuring the efficiency of decision-making units. Eu- 
ropean Journal of Operational Research, v.2, p. 429-444, 1978.

Coelli, T., Prasada, R., Batese, G. An introduction to efficiency end productivity analysis. Kluwer Academic Publishers, USA, 1998.

Cooper, W. W., Seiford, L. M., Tone, K. Data Envelopment Analysis: a comprehensive texto with models, applications, references and DEA-solver software. Kluwer Academic Publishers, USA, 2000 .

Entani, T., Maeda, Y., Tanaka, H. Dual models of interval DEA and its extensions to interval data. European Journal of Operational Research, v. 136, p. 32-45, 2002.

Lorentziadis, P. L. Post-objective determination of weights of the evaluation factors in public procurement tenders. European Journal of Operational Research 200, p. 261-267, 2010.
Narasimhan, R., Talluri, S., Mendez, D. Supplier evaluation and rationalization via data envelopment analysis: An empirical approach. Journal of Supply Chain Management 37 (3), p. 28-37, 2001.

Soares de Mello, M. H. C., Soares de Mello, J. C. C. B., Ângulo Meza, L. Modelos DEA para avaliar a atratividade dos cursos de engenharia da UFF. XXVIII Encontro Nacional de Engenharia de Produção. Rio de Janeiro, 2008.

Soares de Mello, J. C. C. B., Ângulo Meza, L., Gomes, E. G., Biondi Neto, L. Curso de Análise Envoltória de Dados. Simpósio Brasileiro de Pesquisa Operacional. Gramado, 2005.

Yamada, Y., Matui, T., Sugiyama, M. New analysis of efficiency based on DEA. Journal of the Operations Research Society of Japan, v. 37, n. 2, p. 158-167, 1994. 